\title{
Fostering Students' Creativity Through Video Game Development
}

\author{
Ximena López \\ IT, Cognition and Education \\ Initium Studios \\ Rome, Italy \\ ximena.lopez@initium-studios.com
}

\author{
Carlo Fabricatore \\ Computing Department, WBS \\ University of Worcester \\ Worcester, UK \\ c.fabricatore@worc.ac.uk
}

\begin{abstract}
This study focuses on the impact of video game development as an approach to educate individuals for the demands of creative industries such as video games. Questionnaires were administered to 38 students enrolled in two educational programs which involved developing video games. Findings suggest that developing video games creates an exceptional setting to promote the students' creativity, due to characteristics of the task and of the work environment generated by this activity.
\end{abstract}

Keywords- creativity, contextual factors, task characteristics, video game development, game development education.

\section{INTRODUCTION}

As society evolves in an ever more globalized world, the importance of creativity in education becomes a central issue. Current research suggests that the inventiveness and adaptability of creative graduates allow them to explore new markets and clients, with consequent benefits in earning a living amidst the current economic downturn [3]. Hence, educational initiatives aiming at developing high-quality professionals should be focused on approaches benefiting creativity development.

Without neglecting the importance of personal factors, the literature regarding creativity development suggests that there are task and context characteristics that promote the emergence of creative processes and results. The purpose of this study is to explore if these characteristics are perceived by students in the context of game development educational initiatives, and if their perception is associated to the selfperceived creativity improvement.

\section{CREATIVITY AND VIDEO GAME DEVELOPMENT}

In spite of the current economic downturn, in 2010 the global video game market has confirmed its strength in the arena of creative industries. Game development requires high levels of creativity and large numbers of creative people [1]. However, students applying to game development education programs may not have high and uniform initial individual levels of creativity. Thus, in order to foster student employability, educational programs should create learning environments generating contextual factors that foster, encourage and support the development of creativity.

\section{A. Creative Environments and Task Characteristics}

Work by Amabile and colleagues [4] indicates that the production of creative ideas in the workplace depends not only on the employees' individual characteristics, but also on the perception of the environment where they work. Challenge, autonomy, support to new ideas, proper allocation of resources, playfulness, tolerance to failure and diversity of the work group have been identified as the main characteristics of the social microenvironment influencing creativity of workgroups.

Special attention has also been given to the relationship between task characteristics and creativity. Shalley and Gilson [5] indicate that highly complex and challenging tasks make workers more persistent and more likely to explore alternative approaches, which should result in more creative outcomes. Mumford [6] shows that creative work can occur when the tasks presented involve complex, illdefined problems requiring the generation of novel, useful solutions. Oldham and Cumming [1] indicate that complex tasks encourage creativity by demanding to focus simultaneously on multiple dimensions of the work being tackled.

\section{B. Enhancing creativity through video game development}

Although little research has been carried out (e.g. [1]; [2]), some findings support the idea that video game development generates the contextual conditions that would allow students to develop creative skills. Game developers need to work in interdisciplinary teams to master complex technologies and deal with often sophisticated themes to produce creative contents palatable to their target audience. Sub-teams are required to simultaneously work on different interdependent tasks, where progress in one area depends on progress in the others [1][2]. Furthermore, developing games is an extremely complex, often ill-structured process, requiring teams to juggle many alternative ideas, for each one of which there are many possible implementations. There is a continuous and circular flow of idea creation and evaluation [1][2]. As new problems are discovered and new ideas and solutions are subsequently developed and implemented, further problems and new opportunities arise, thus leading to a new iteration. This circular process emphasizes continuous creativity through problem finding, problem solving and implementation of solutions.

\section{METHOD}

A total of 38 male students participated in this study, with ages ranging between 19 and 32 (mean=21.7, SD=3.7). Participants were students of two Italian study programs covering multimedia software design and development. 
These programs used an authentic learning approach, providing to students a learning context that reflects the way knowledge and skills are used in a real work environment. In addition to courses in game design, programming, graphic arts, sound and multimedia design, students were involved in a game production internship, which lasted four to six months. Tutors supported the students throughout the development process.

A 33 item questionnaire was created to collect students' perceptions regarding contextual and task characteristics of the learning environment. Based on the literature [4][5][6], items were formulated as propositions to be rated on a 5point Likert scale ( $1=$ Strongly disagree, $5=$ Strongly agree). Perceived creativity improvement was measured by students' rates to the item "I think I developed my creativity thanks to participating in this course". Internal consistency of the questionnaire was 0.77. An electronic copy of the questionnaire was sent by e-mail to all the students of the courses during the last week of classes. Questionnaires were returned by $85 \%$ of students.

\section{RESULTS AND DISCUSSION}

A descriptive analysis of the items was carried out. Table 1 shows the percentage of students agreeing or strongly agreeing with the item statements. Results suggest that developing video games to educate individuals for the creative industries recreates a working atmosphere that supports creativity. Particularly, it appears that the main characteristics promoted were the encouragement to critically analyze their own work, and to search, generate and present new ideas, all of which are described by different researches as creativity-fostering characteristics [4][5]. Moreover, the learning environment fostered the acknowledgement of new ideas that were good, which parallels research focusing on the importance of recognition and credit to promote creative motions [5]. Other context features identified by students were the team's commitment to work, the diversity of skills and interests of participants and trust in others' work. This is consistent with previous studies [4][5] showing that creativity may occur through diversity in team members' backgrounds, challenging of ideas, and shared commitment to work. Only two contextual characteristics, i.e. adequate workload and responsibility load, were scarcely perceived by students. Excessive workload and responsibility are said to undermine creativity [4][5]. Thus, it is important that educators who plan to use video game development in their educational programs consider that this task can be very complex and demanding, for both students and tutors. Task characteristics identified by the literature as creativity promoters [1][2][5][6] were perceived by most of the students, in particular the iterative and complex nature of video game development.

Most students $(84.2 \%)$ perceived that they had developed their creativity thanks to the courses. There is a positive correlation between the students' perception of the contextual characteristics (as a scale) and the perception of their own creativity improvement $(\rho=0.76, p=0.000)$. There was no significant correlation with the tasks characteristics taken as a scale.
TABLE I. CREATIVE CARACTERISTICS AS PERCEIVED BY STUDENTS

\begin{tabular}{|c|c|}
\hline Characteristics Associated with Creativity & \% students \\
\hline \multicolumn{2}{|l|}{ Contextual } \\
\hline Encouragement to analyze own work & 97.4 \\
\hline Participants' commitment to work & 92.1 \\
\hline Encouragement to present ideas & 86.8 \\
\hline Encouragement to search for new ideas & 86.8 \\
\hline Participants with different skills and interests & 81.6 \\
\hline Opportunities for initiative & 81.6 \\
\hline Trust in others' work & 78.9 \\
\hline Acknowledgement of good ideas & 78.9 \\
\hline Team interdependence & 68.4 \\
\hline Fluent communication tutors-students & 65.8 \\
\hline Encouragement for autonomy & 65.8 \\
\hline Impartiality & 63.2 \\
\hline Tutors as creative models & 60.5 \\
\hline Motivating/ stimulating work climate & 57.9 \\
\hline Possibility of assuming risks & 57.9 \\
\hline New ideas welcomed by participants & 55.3 \\
\hline Playfulness & 52.6 \\
\hline Adequate responsibility load & 15.8 \\
\hline Adequate work load & 7.9 \\
\hline \multicolumn{2}{|l|}{ Task } \\
\hline VG development as circular and iterative process & 94.7 \\
\hline VG development as complex and demanding & 92.1 \\
\hline Importance of creativity for all team members & 68.4 \\
\hline Need for creativity during the whole process & 68.4 \\
\hline VG development not only for the creative people & 57.9 \\
\hline
\end{tabular}

We believe that task and contextual characteristics of video game development found in this study also foster the development of other skills and competences, such as teamwork and problem-solving. Thus, video game development may be a remarkable tool not only to develop students' creativity but also crucial skills necessary to face the increasingly demanding labor market.

\section{REFERENCES}

[1] F. T. Tschang, "When Does An Idea Become an Innovation? The Role of Individual and Group Creativity in Video game Design". Proc. DRUID Summer Conference, Copenhagen Business School, June 2003.http://www.druid.dk/uploads/tx_picturedb/ds2003-871.pdf.

[2] M. Walfisz, P. Zackariasson, and T. Wilson, "Real-time strategy: Evolutionary game development”, Business Horizons, vol. 49, 2006, pp. 487-498.

[3] R. Bridgstock, "Skills for creative industries graduate success", Education \& Training, vol. 53(1), 2011, pp. 9-26.

[4] T. M. Amabile, R. Conti, H. Coon, J. Lazenby, and M. Herron, "Assessing the work environment for creativity", Academy of Management Journal, vol. 39(5), 1996, pp. 1154-1184.

[5] C. E. Shalley and L. L. Gilson, "What leaders need to know: A review of social and contextual factors that can foster or hinder creativity", Leadership Quarterly, Vol. 15(1), 2004, pp. 33-53.

[6] M. Mumford, "Managing creative people: strategies and tactics for innovation", Human Resource Management Review, Vol. 10(3), 2000, pp. 313-351.

[7] G. Oldham, and A. Cummings, "Employee Creativity: Personal and Contextual Factors at Work", Academy Of Management Journal, Vol. 39(3), 1996, pp. 607-634. 